\section{COMPLICATIONS OCCURRING IN PLEURISY.}

By Michatl G. FOSTER, M.A., M.B. CantaB.; AND

ALFRED E. THOMSON, M.D. R.U.I., M.R.C.S. \&C., HOUSE PHYSICIAN TO THE GENERAL LYING-IN HOSPITAL, YORK-ROAD, LAMBETII, $S \mathrm{E}$.

SUDDEN death occurring in pleurisy is a rare event and any general explanation of its cause is unsatisfactory. The following case, though not, perhaps, throwing much light on the subject, is, we think, worthy of record on account of its sudden termination and interesting complications.

The patient's family history was good; her brother and sister are healthy; her father died from small-pox at an advanced age, but was said to have had a "weak heart" and had frequent attacks of congestion of the lungs; her grandfather died of rheumatic gout at thirty-five years of age. The patient was forty-five years of age, had been married fourteen years, but had never borne children. She enjoyed good health till four years ago, when she began to suffer from pain and frequency of micturition with pyuria, evening pyrexia and aching pain in the right loin and hypogastrium. The symptoms became more urgent and nephrectomy was proposed but was not performed. She had, however, some ulceration of the bladder scraped two years and a half ago. In the few months that followed her health gradually improved and her symptoms became less severe. The urine, however, never became clear, the amount of pus varying. Tubercle bacilli were found on one occasion. More recently she had pain in the left loin and when we first saw her it was to the left side that she drew our attention in speaking of her kidney trouble. She arrived in Italy last December. Throughout February she complained of pain in the left loin and during the last ten days of that month of pain in the left shoulder, in "the side" and over the left crista ilii. She was told that the pain was pleuritic ; she was not, however, kept in-doors, and she proceeded in a few days to a neighbouring town, where the pain was attributed to some nephric or perinephric inflammation, which opinion was strengthened by an evening pyrexia and a doubtful fulness in the region of the left kidney. She had been confined to bed five days previously to our first visit and her friends reported having noticed occasional attacks of breathlessness during conversation. She knew of no cause for her illness and could not fix any exact date for its commencement. On the night of Feb. 27th she awoke with intense pain below and outside the left nipple, which continued without much change till after aspiration. On our visit on Feb. 28th the patient was propped up in bed, inclined to the right side. She was in great distress and somewhat livid, complaining of intense pain over the area outside and below the left nipple, also of pain, though less severe, over the left shoulder. The temperature was $100 \cdot 5^{\circ} \mathrm{F}$., the pulse was 130 and the respiration 48 There was slight fulness above and below the left clavicle, which was not tender, nor did it pit on pressure. Movement, of the left side was much impaired and cough and vocal fremitus were absent. On percussion there was absolute dulness over all the left lung, back and front, with increased resistance. The breath sounds werevery faintand tubular. The right lung was dull behind up to the angle of the scapula and there was crepitation ; above it was hyper-resonant. The heart could not be distinguished by percussion nor could its impulse be felt. The sounds were most intense behind the right border of the ensiform cartilage ; on tracing them outwards towards the normal position they became suddenly suppressed an inch to the left of the sternum. They were feeble in character, but not otherwise changed. The kidneys could not be palpated very thoroughly owing to the intense pleuritic pain and dyspncea, but she did not complain on fairly firm pressure. There was no tenderness in the region of the hypogastrium and no cdema of the legs. The urine was acid, sp. gr. 1020, with traces of albumen and a deposit of pus (one-sixth). Microscopically there were few formed cells, but abundant granular débris. She was ordered a mixture composed of carbonate of ammonia, digitalis, strychnia and ether, and $8 \mathrm{oz}$. of brandy, 2 pints of beef-tea, $1 \mathrm{oz}$ of beef extract and 2 pints of milk. On March 1st the general con. dition of the patient was worse. A Potain's aspirator was inserted in the sixth space in the mid-axillary line, but no fluid cameaway. She complained of great pain orer the left shoulder.
The next day the aspirator was inserted at the same level, but one inch and a half nearer the spine and one litre of turbid serum with flakes of lymph was aspirated. There was no cough during the operation, so the pleura was emptied and the puncture closed with cotton-wool soaked in collodion and with strapping. The aspiration gave great relief to respiration, and she made no further complaints of pain over the shoulder. On the morning before the aspiration the temperature was $101^{\circ}$, the pulse 135, and the respiration 42 . In the evening afterwards the temperature was $100 \cdot 6^{\circ}$, the pulse 122 and the respiration 34. The following day the temperature was $98.4^{\circ}$, the pulse 110, and the respiration 30 ; she had passed a good night. The left lung on percussion above a line running from the second costal cartilage to the anterior axillary fold gave a clear, high-pitched note of tympanitic quality (Skodaic resonance). Below this line there was a highpitched more toneless note, devoid of any tympanitic quality. Behind up to the sixth spine a tubular stomach note was elicited ; above this a high-pitched note slightly deficient in tone with quality unchanged. Nowhere was there complete dulness. A few crepitations were audible over the left apex; over the remainder of the lung faint tubular breathing was heard. Both dulness and crepitations at the base of the right lung were much diminished. The heart's impulse conld be felt in the right fourth interspace close to the sternum. The cardiac dulness extended one inch to the right of the sternum. On March 5th the temperature, respiration and pulse were about the same, and remained so till death. Dulness and crepitation at the base of the right lung were very slight. There was no change in the character of the sounds on percussing the left lung, but Skudaic resonance had increased to the level of the third rib in front; behind, the stomach note extended upwards to the level of the fourth spine. She was ordered a mixture of iodide of potassium (5gr.), with acetate of ammonia and digitalis. There was no further change in the physical signs in the chest. The improvement in her general condition continued and she was fairly comfortable and had little pain, whilst the dyspncea was not distressing. Slight cedema of the left fingers and hand appeared and increased gradually, with tingling pain. On March 7th the whole arm and hand were involved in the firm white swelling, which diminished gradually over the shoulder and left side of the neck. The tissues did not pit readily; both brachial and radial vessels pulsated; the brachial vein was slightly tender for about an inch of its course and the external jugular extremely so. There was no enlargement of the axillary glands. The arm was kept elevated on pillows, wrapped in cotton wool and a warm lead and opium lotion was applied. The deposit in the urine decreased and she passed on an average from forty to fifty ounces per diem. There was no further change in the signs, symptoms or general condition till March 9th. The arm gave her little trouble; she took nourishment well, talked cheerfully and was interested in things around ber. At 10 A.M. on March 9th she suddenly complained of great pain to the right of and below the ensiform cartilage with dyspnca, and died in ten minutes.

Necropsy.-The body was well nourished. There was swelling of the left upper extremity with staining over the external jugular vein. The heart lay behind the sternum and there was a large amount of superficial fat covering it. About six drachms of serous fluid escaped from the pericardium. The serous membrane was pale, smooth and glistening, the walls were thin and pale but firm to the touch, and the endocardium and valves were normal. The cavities were empty, but the aorta, pulmonary arteries and vena cava contained dark fluid blood; the vessel walls within the thorax were normal. The right lung was crepitant and normal; there were slight old pleural adhesions. Of the left lung all the lower part and about half of the upper were completely collapsed, airless and slate-blue in colour, the apical portion of the upper lobe being expanded and crepitant. The whole pleura was red and cedematous and there was much gelatinous lymph of recent formation about the base and sides. There were no tubercular deposits in either lung. The spleen was enlarged and softened. The right kidney was enlaroed and there was much perinephritic thickening. The surface was covered with numerous hemispherical elevations, and on section the kidney showed advanced pyo-nephrosis, the pelvis being greatly thickened and the tubular structure completely destroyed. The cortex was converted into saccules which communicated with each other and contained white inspissated pus with small gritty particles. The saccules were bounded by thick fibrous walls lined by smooth membrane which 
formed septa between them. The ureter was thickened but pervious. The bladder showed no trace of disease. The left kidney was much hypertrophied, being about one and a half times the usual size. It was globular in form and movable. The tissue was normal and there was no trace of tuberculosis. The uterus, tubes and ovaries were normal. An examination of the cranium or great veins of the neck was not allowed.

Remarks.-This case is a striking example of a primary tuberculous lesion remaining confined for fonr years to one kidney, without secondary deposits appearing either in the lungs or other organs and without any direct extension along the genital or urinary tracts. The globular form of the left kidney, presumably assumed during its compensatory hypertrophy, apparently favoured its becoming mobile, not only by its increased bulk projecting into the abdominal cavity but also by its raising up the peritoneum and by its change of contour. Clinically this condition of the kidney is of great importance, for there was the great probability that pain and enlargement of the left kidney, occurring consecutively to similar events in the right with cystitis, were due to extension of tubercularisation to the other organ. But such an inference would entirely mislead the surgeon when weighing the pros and cons of operative treatment. Catheterisntion of each ureter would be of great service, and also the fact that the pain subsided after a few days' confinement in bed. The symptom of pain gave rise to some confusion, but the nephritic pain was of many months' standing, whilst the recent shoulder pain probably marked the onset of the pleurisy. The intense pain which came on in presence of the large effusion, and which subsided after aspiration, seems rather to have been due to pressure on inflamed nerve endings than to any friction of opposed surfaces, as the lung was collapsed and relief followed aspiration. The case illustrates some interesting points as regards the percussion note commonly known as Skoda's resonance. Its cause is obscure and the current theories of its causation somewhat at variance. Whether this sign was present during the accumulation of the fluid we do not know, but after complete withdrawal of the fluid it made its appearance and remained unchanged except for a slight increase in area for ten days, when the necropsy demonstrated absence of fluid, either free or loculated. The effusion therefore probably caused the changes in the lung which gave rise to the Skodaic resonance, but its actual presence was not an essential factor for its maintenance, though undoubtedly the two are generally found together. Effusion acts merely as the exciting cause of other conditions, which appear to be diminution of the respiratory area of the lung in one part with airlessness varying in degree, and a remaining crepitant part in contact with the parietes. Though its commonest cause is fluid effusion, a similar phenomenon has been observed above hepatised lung. Dr. Wilson Fox has collected and summarised the recorded cases of sudden death in pleurisy with the probable and rerified causes of death. We quote those in which an interval elapsed between paracentesis and death and in which the result was not directly due to the operation. - Case 1: Death whilst washing out the pleural cavity one month after paracentesis. Hæmorrhage into the septum of the heart was found at the necropsy. - Case 2 : Fatal syncope on the seventeenth day. The heart was fatty and contained a thrombus which extended into the pulmonary artery.-Case 3 : Death on the thirteenth day; no cause discovered.-Case $4:$ Death on the twelfth day whilst walking upstairs, probably due to pulmonary embolism. - Case 5: Death forty-eight hours after operation (probable thrombosis of great veins of the neck) unverified - Cases 6 and $\%$ : Death on the tenth and nineteenth days respectively from pulmonary hæmorrhage. Potain, Vallin and Lépine have also recorded cases in which paracentesis was not performed, in which death resulted from cerebral embolism. Comparing this case with the latter series it will be observed that there were no symptoms whatever of cerebral embolism. Of the former series it bears most resemblance to Cases 2,3 and 5 , especially considering the presence of phlebitis of the external jugular and axillary veins. The analogy was not, however, borne out by the post-mortem examination, when neither thrombosis nor embolism was found in the heart, lungs or thoracic ressels. We noted that though the displacement of the heart was considerable it had not interfered with the normal calibre of the great vessels. Cardiac failure rather than paralysis of the respiratory centre appeared from the final symptoms to be the cause of death. The heart was organically weak ; it was subjected to the additional tax of pressure and displacement for a considerable period, at a time, too, when aeration of its blood-supply was seriously interfered with. We believe the heart under such adrerse circumstances was unable longer to combat successfully the increased peripheral resistance offered by the diminished lung area and succumbed under the difficulties we have indicated.

San Remo, Italy.

\section{TWO FATAL CASES OF POISONING BY STRYCHNINE.}

BY HENRY PILKING.TON, M.R.C.S. \&c.

CASE 1.-On July 13th, 1892, I was called at $6 \mathrm{~A}$. M. to see a young woman aged seventeen, who was thought to be in a fit. On arriving at her abode (about seven or eight minutes' walk) I found the girl fully dressed and lying on a sofa, with traces of having recently vomited. She was quite unconscious, the face was livid, the pupils were contracted, and the jaws were partially clenched; the pulse was about 90 , rather weak; and there were convulsive movements of the extremities and slight spasmodic twitchings of the fingers like subsultus tendinum. Her parents stated that she had risen about 5 A. M. apparently quite well, and to their knowledge had taken nothing, not even her usual cup of tea. They could not remember that she had that morning been apartfron some one or more members of the family for even five minutes. Their statements were somewhat contradictory, but that might have been due to their distress or anxiety. I left to get some remedies, having given instructions to keep anything she might vomit during my absence. When I returned I found the girl was much worse. She had vomited about one ounce of greenish fluid and had been much convulsed, and her face was darker and respiration was slow and laboured; the pulse was about the same ; and there were still convulsive twitchings as when I left her. The respiration slowed until she only gave an occasional gasp. She died about an hour after I first saw her, or about an hour and a half from the beginning of the attack, the pulse beating regularly during and even after her last gasps. I reported the case to the coroner and police as a death not due to natural causes. I was informed that, after inquiring into the circumstances, it was not deemed necessary to hold an inquest and there was no necropsy. For my own satisfaction I submitted the small quantity of vomit to an analyst and he sent me a certificate to the effect that he had found strychnine in it.

CASE 2 - On April 10th, 1893, I was called to see a man residing four miles from my house. He was a chemist and druggist, twenty-nine years of age, of very regular habits and fond of athletic exercises. At $11.30 \mathrm{~A}$. M. the same day he was seen by a friend and made arrangements to meet him at the cricket ground that afternoon. Twenty minutes afterwards the patient's brother called at the shop, and seeing several customers waiting to be attended to, he entered the kitchen behind and found his brother lying on the floor quite unconscious and observed that he had vomited recently. Local assistance was called in and I was telegraphed for. I arrived at 230 P.M. (two hours and three-quarters after the patient had last conversed with his friend) and found him to be in the following condition: He was lying. on the floor quite unconscious; the eyelids were very puffy and red; the pupils were very uneven, the right being contracted and the left dilated; the pulse ranged from 84 to 90 : the temperature was $1008^{\circ}$; he had convulsions at quick ard: irregular intervals, started by the slightest touch, even that of feeling the pulse; there was inability to swallow, but notrismus; and the fingers were clenched over the thumbs and the toes were incurvated. He had romited, but unfortunately the vomit had been removed from the floor and could not be collected. With the acquiescence of the practitioner present I gave an enema containing 30 grs. of chloral hydrate. Afterwards the convulsions decreased in number and sererity, and the pupils became equal in size some little time before death. I was with the patient about three hours, during which time his pulse continued to be good, but about 5 P. M. respiration became very laboured and gradually slowed, so that when I left at 5.20 P.M. he was only gasping at long intervals, although the pulse was regular and only a little weaker. He died seven or eight minutes after I left him.

Post-mortem examination, trenty-tis hours after death.- 